\title{
A Prosthetic Alternative Treatment for Severe Anterior Ridge Defect using Fixed Removable Partial Denture Andrew's Bar System
}

\author{
Ashish R Jain
}

\begin{abstract}
It has been well documented that anterior ridge defects present in a patient are very difficult to treat properly. These defects have been treated with great amount of planning and complexities while using the conventional treatment approaches like removable or fixed prosthesis and options of implant. Though totally implant-supported restorations are very successful, dentists may resort to prescribe implant overdentures because of functional, anatomical economical or esthetic considerations. However, the loading conditions of the partially implantsupported overdenture may affect the long-term predictability of this type of restoration. The concept of the Andrew's bar system can be utilized. In some cases the Andrew's bar system is superior to the implant-supported fixed partial denture and other techniques for implant overdentures. The purpose of this article is to evaluate and describe the Andrew's bar system (a fixed removable partial denture), to treat a class III anterior ridge defect using natural teeth as abutments for its fixed component followed a removable component. The use of Andrew's bar system over implants offered the dentist another option in meeting patient's needs.
\end{abstract}

Keywords: Andrew's bridge, Class III ridge defect, Bar attachment.

How to cite this article: Jain AR. A Prosthetic Alternative Treatment for Severe Anterior Ridge Defect using Fixed Removable Partial Denture Andrew's Bar System. World J Dent 2013;4(4):282-285.

Source of support: Nil

Conflict of interest: None declared

\section{INTRODUCTION}

It has been well documented that anterior ridge defects present in a patient are very difficult to treat properly (especially esthetically). However, to treat such defects when edentulous anterior portion of maxillary ridge has both inadequate height and width; the conventional options of fixed partial dentures (like bridges) or implant supported fixed partial dentures are not enough. For such cases where replacement of teeth along with the supporting structures necessary for esthetics can be achieved by placing 'Andrew's bridge'. 1

Andrew's bridge was developed when all the conventional fixed or removable partial dentures were not successful in treating severe residual ridge resorption or jaw defect cases either due to trauma and/or surgical ablation and to improve or achieve comfort, hygiene, normal phonetics and mostly normal esthetics. It was Dr James Andrews of Amite,
Louisiana, who introduced the fixed removable Andrew's system (Institute of Cosmetic Dentistry, Amite, LA). The Andrew's system was constructed from a fixed bridge with removable pontics. ${ }^{2,3}$ The fixed bridge is made of PFM crowns, fused to a premanufactured bar that is permanently cemented to the prepared abutment, while the removable pontics are made of metal sleeve tract embodied within an acrylic removable partial denture. This technique possesses the advantage of flexibility in placing denture teeth as well as the stabilizing qualities of a fixed prosthesis. This article thus explains the procedure of fabricating and correcting a ridge defect using a pontic supported fixed removable Andrew's bridge.

Various treatment options available to treat such ridge defects:

- Soft tissue procedures include various options like:

- For class I defects- the roll technique.

- For class II and III defects - the interproximal graft technique

- Free gingival graft ${ }^{1}$

- The onlay graft for augmentation of ridge width and height.

- Bone grafting-using inlay and onlay grafting techniques with either autogenous grafts, allografts or xenografts.

- Combination of (a) and (b)-includes ridge augmentation using bone grafts followed by implant placement.

- Other methods include removable partial dentures, fixed partial dentures with pink ceramic, fixed-removable partial dentures (Andrew's bridge). ${ }^{2}$

\section{INDICATIONS}

a. Absolute indications

- Excessive residual ridge defect.

- Ridge defects/jaw defects either due to trauma and/ or surgical ablation.

- Cleft palate patients with congenital or acquired defects. ${ }^{4}$

b. Relative indications

- Often fixed partial denture failure with badly damaged, cracked or weakened teeth by fillings and disproportionate teeth. ${ }^{5}$

- Sometimes could be used in patients with periodontal problems. $^{6}$ 


\section{ADVANTAGES}

a. It includes all the advantages of fixed and removable partial dentures with better esthetics, hygiene along with better adaptability and phonetics.

b. It is comfortable and economical for patients.

c. There is no plate as in RPD.

d. No soft tissue impingement and the surrounding structures.

e. The system acts as stress breaker while transmitting unwanted leverage forces.

The Andrew's system is usually of two types based on the area of bar attachment:

a. Pontic supported.

b. Bone anchored or implant supported Andrew's bar system.

This article thus explains the procedure of fabricating and correcting a ridge defect using a pontic supported fixedremovable Andrew's bridge. ${ }^{7}$

\section{CASE REPORT}

A 32-year-old male patient came to the clinic (Maruthi Dental Clinic, Sowcarpet, Chennai, India) with a complaint of missing teeth in upper front tooth region of jaw (Fig. 1). Upon questioning the patient revealed discoloration in upper front teeth and history of sports trauma 10 years back. As the patient at that time was not willing for treatment he underwent extraction of all four involved teeth $(11,12,13$, 21). Present radiographs of that region further showed loss of residual ridge both horizontally as well as vertically, along with presence of flabby tissue (leading to a class III type defect) thereby clinically making the implant placement a questionable procedure (as placement of bone graft material in a three-sided defect makes implant placement a questionable procedure due to the property of osseointegration) (Fig. 2). Also mini-implant or small diameter implant is also questionable due to lack of proper bone height and support and class III defect. The patient was not willing for surgical bone grafting along with inplant placement. Hence, treatment with Andrew's bridge was chosen. The whole procedure along with its advantages and disadvantages was explained to the patient and an informed consent was taken.

\section{TREATMENT PROGRESS}

The following sequential steps were followed for treating the case:

For this system the maxillary first and second premolar on right side and lateral incisor and canine on the other side were taken as abutments to support the Andrew's system.
Firstly, diagnostic casts were prepared using an alginate as impression material and the whole treatment was planned accordingly.

Then the selected abutment teeth were prepared for metal ceramic crowns and again impressions were recorded using the putty wash technique (Polyvinylsiloxane, Dentsply, Aquasil Putty Material) and master casts were poured in dental stone (Type IV).

Old RPD was refitted in the patient's mouth along with the temporary restorations/crowns.

Later on, wax patterns were made on the prepared teeth which were connected using a preformed plastic bar attachment (Ceka Attachments, Preciline), adapted according to the curvature of the ridge and was attached to the abutment teeth as posteriorly as possible.

The whole pattern was then casted in chrome cobalt alloy and this metal framework was tried in the patient's mouth and was checked for clearance between the bar attachment and underlying soft tissues.

After satisfactory trial in and shade selection was done for the ceramic. The metal crowns were then covered with a ceramic layer and the whole restoration was finished and polished, then the temporaries were removed and the fixed component of the Andrew's system were cemented over the prepared teeth (Fig. 3).

Then with the crowns in position, along with the bar, an alginate impression was made and a stone cast was poured (Fig. 4).

Later on, the missing teeth were arranged in the wax rim and trial was done, which was further replaced by pinkcolored heat cured acrylic resin with a clip placed in the lingual aspect to attach this RPD over the bar attachment (Figs 5 and 6).

Later, patients was trained to properly place and remove the RPD fabricated over the fixed component of Andrew's bridge and proper oral hygiene (including interdental brush) instructions were given to the patient (Figs 7 and 8).

Periodic recall was done to check for the adaptability and assess the success of the treatment.

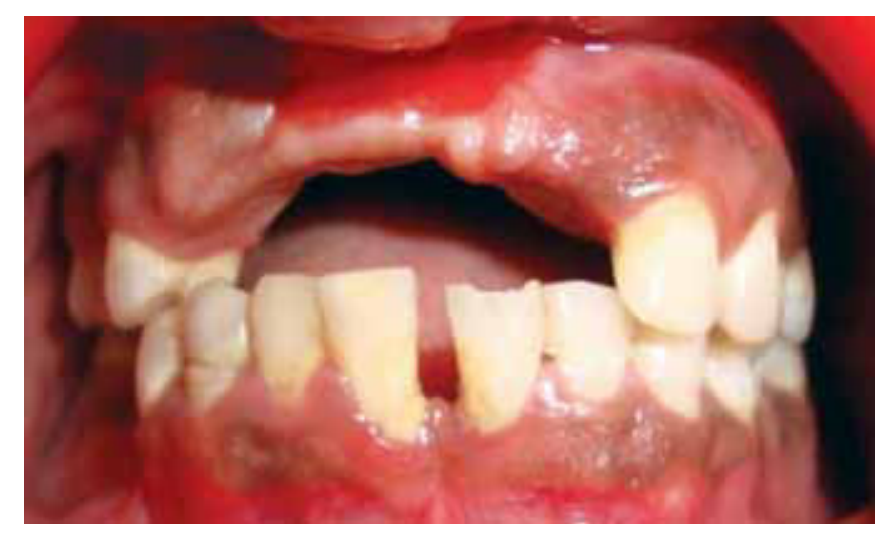

Fig. 1: Class III residual ridge defect in the patient's oral cavity to be corrected using Andrew's bar system fixed removable prosthesis 


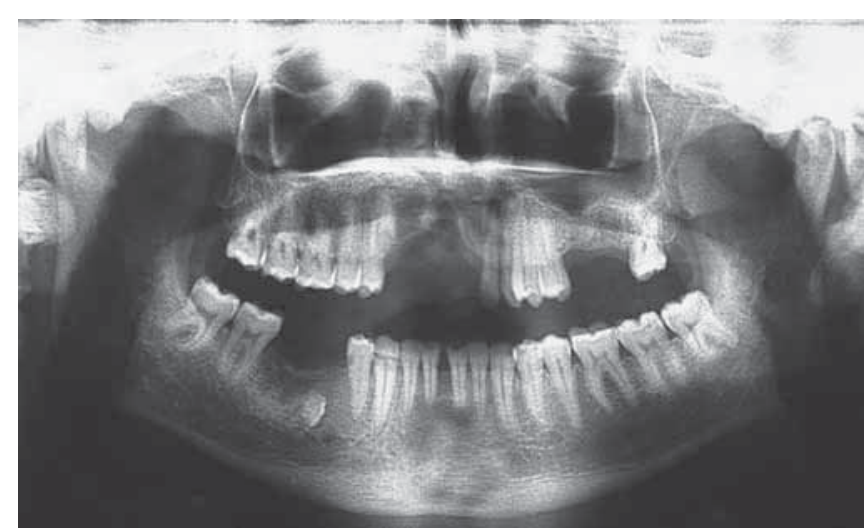

Fig. 2: Preoperative OPG of a patient

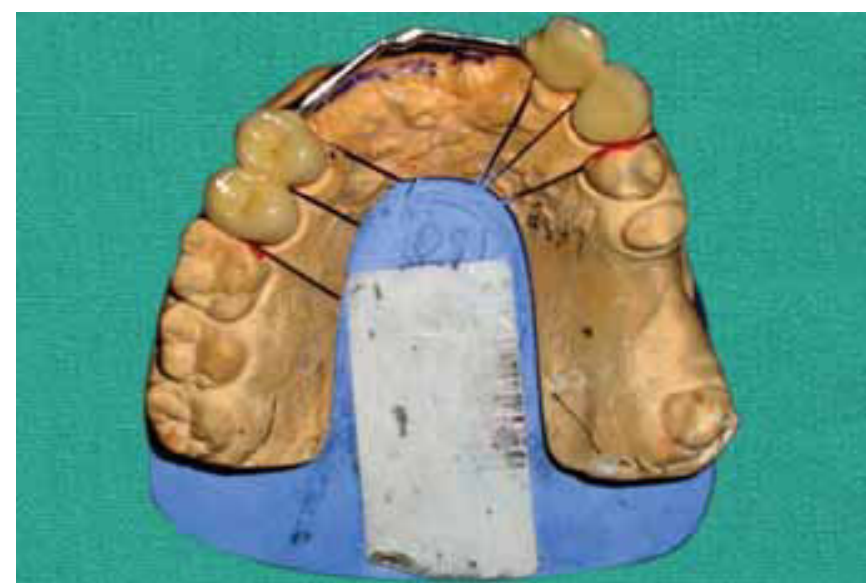

Fig. 3: Final metal-ceramic restoration of abutment teeth along with the Andrew's bar on the cast

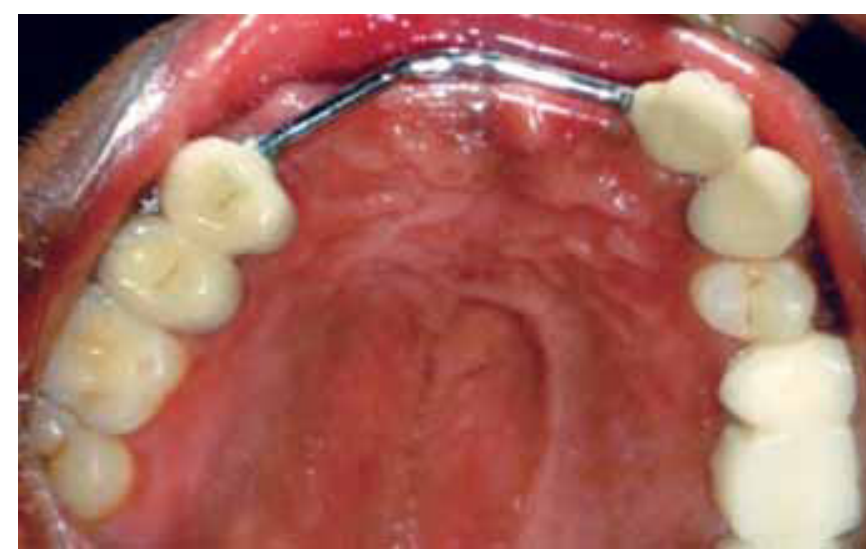

Fig. 4: Final metal-ceramic restoration of abutment teeth along with the Andrew's bar being checked for proper clearance from the underlying soft tissues and bone

\section{DISCUSSION}

The concept and advantages of the conventional Andrew's system are adequately reported in the literature and textbooks when compared to the implant supported fixed partial dentures. ${ }^{7-11}$ The pontic anchored Andrew's system provides maximum esthetics and optimum phonetics in cases involving considerable supporting tissue loss, jaw defects

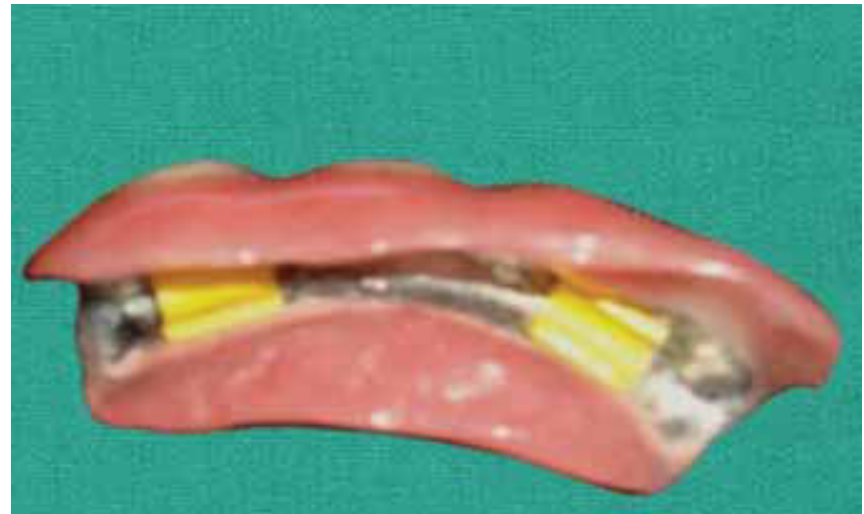

Fig. 5: Heat-cured acrylic resin RPD with the clip for bar attachment

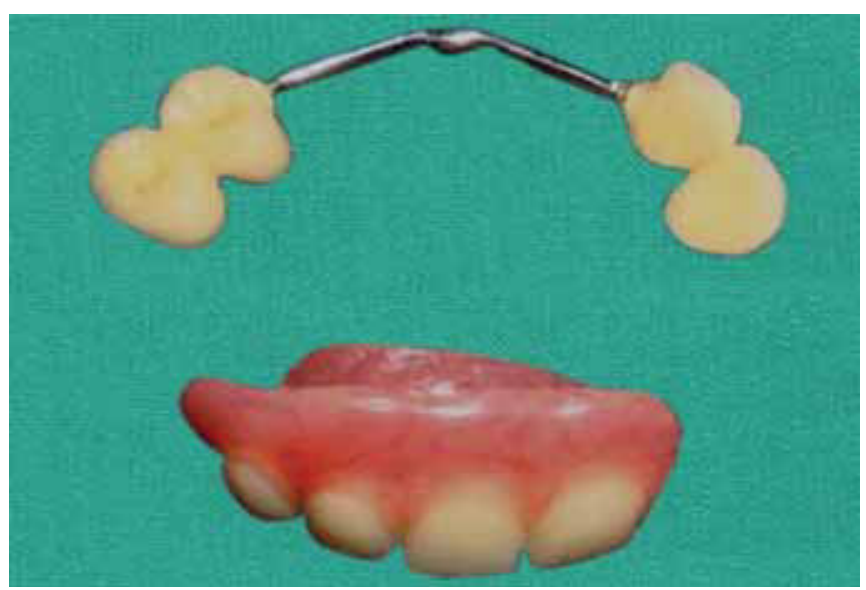

Fig. 6: Andrew's bar system

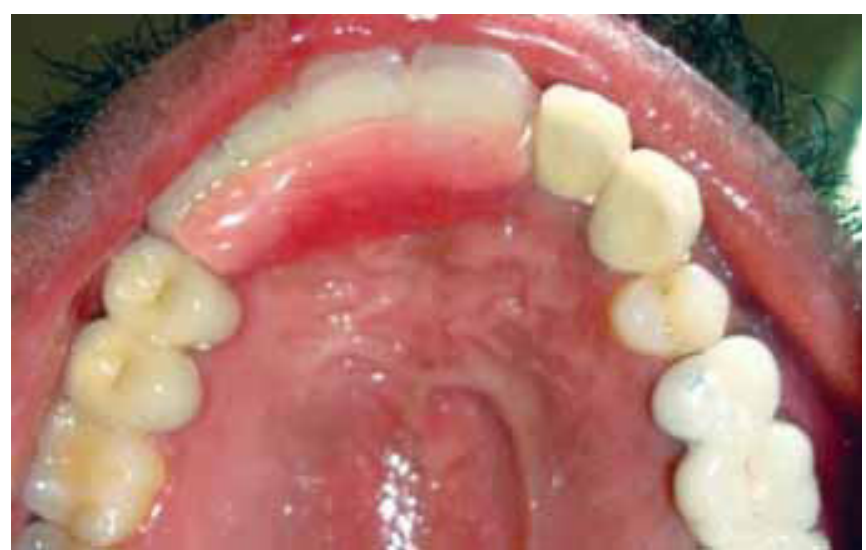

Fig. 7: Final completed Andrew's fixed removable partial denture for the correction of defect in the patient's oral cavity (occlusal view)

(class III ridge defect) and when alignment of the opposing arches and/or esthetic arch position of the replacement teeth create difficulties. Otherwise, overly long pontics slanted to contact the residual ridge are often the end result when utilizing implant/fixed restorations in such cases. ${ }^{12}$

Another main advantage of Andrew's bridge system is the criterion of the removable part which can be easily 


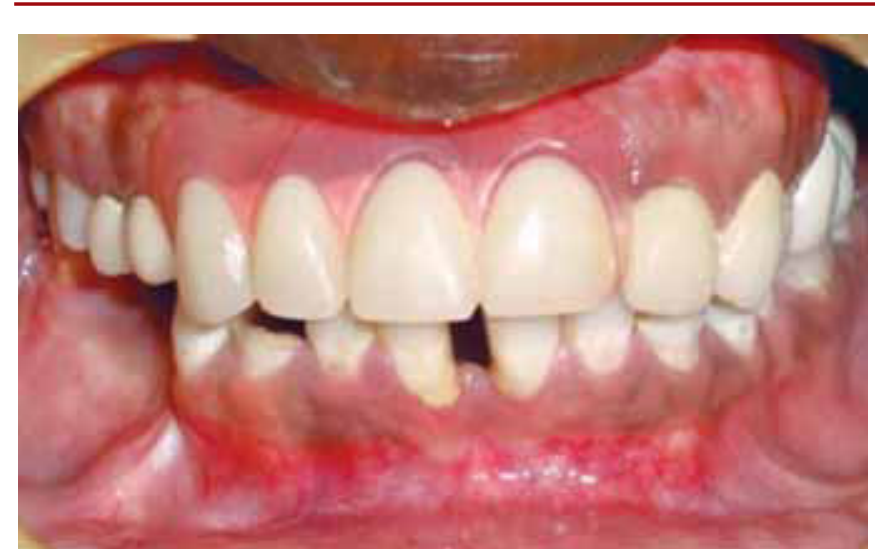

Fig. 8: Final completed Andrew's fixed removable partial denture for the correction of defect in the patient's oral cavity (frontal view)

used by patient for hygienic access to abutments and surrounding structures. Regular or mini-implant placement was a questionable procedure in the above case and the loss of labial cortical bone was not been controlled which led to a class III type of ridge defect. Also the presence of loose flabby tissue and the fact that due to absence of cortical bone at three sides made the implant placement procedure improper because even with the bone grafting in such cases the success of osseointegration is questionable. ${ }^{13,14}$

The Andrew's bar and sleeve tract is constructed from a precision machined space-age alloy. With an unusual viscous molecular attraction of fitting and superior resistance to stress corrosion. These unique molecular values, in addition to the precision fit, allow the acrylic segment to be inserted and removed thousands of times without losing retention, whereas the durability of the bar and clip attachment is questionable since the bar and clip are made from two different materials and, eventually, one of them will wear the other. ${ }^{15,16}$

\section{CONCLUSION}

After the patient was treated with this Andrew's bar system, it was evaluated over a long period of time and accordingly it was concluded that the patient had good adaptability, was comfortable and achieved pleasing esthetics and phonetics as desired. Hence, it can be concluded that it can be indicated in patients with severely resorbed ridges where esthetics due to repositioning of teeth creates difficulties hence giving maximum esthetics, hygenics, good fit, along with minimal trauma to soft tissues and surrounding structures or underlying bone at an economical price.

\section{REFERENCES}

1. Tuinzing DB. Preimplant surgery of bony tissues. J Pros Dent 1998;80(2):175-183.

2. Sadig WM. Bone anchored Andrews bar system. A prosthodontic alternative. Cairo Dent J 1995;11(1):11-15.

3. Immekus JE, Aramany M. A fixed-removable partial denture for cleft palate patients. J Pros Dent 1975;34(3):286-291.

4. Gates GN, Boch AJ. Boulder. Prosthodontics-crown and bridges. mht.

5. Stein RS. Pontic-residual ridge relationship: a research report. J Pros Dent 1966 Mar-Apr;16(2):251-285.

6. Nallaswamy. Textbook of prosthodontics. 2 ed. India, New Delhi: Jaypee Brothers Medical Publishers; 2008. p. 606-609.

7. Everhart R, Cavazos E. Evaluation of a fixed removable partial denture: Andrew's bridge system. J Prosth Dent 1983;2:180.

8. Finger I, Block M, Salinas T. Treatment of a resorbed maxilla with sinus grafting, implants and a spark-erosion overdenture: Clinical report. Implant Dent 1992;1:150.

9. Glantz PO. On the biomechanics of implant retained overdenture. EOTC symposium on intraosseous implant supported overdentures. Brussels, Belgium; 1989. p. 218-239.

10. Guerra LR, Finger IM, Block MS. Tissue supported implant overdentures. Implant Dent 1989;1:69.

11. Hansen CA, DeBoer J, Woolsey G. Esthetics and biomechanical considerations in reconstructing and using dental implants. Dent Clin North Am 1992;36:713.

12. Haraldsson T, Jent T, Stalblad PA, Lekholm U. Oral functions in subjects with overdentures supported by osseointegrated implants. Scand J Dent Res 1988;96:235.

13. Mueninghoff L. Fixed removable partial denture. J Prosth Dent 1982;5:547.

14. Rhoads J, Rudd K, Morrow R. Dental laboratory procedures. 2nd ed. St. Louis: CV Mosby Company 1986. p. 187-196.

15. Sillard R. Fixed removable dental implant '*' system. United States patent no. 4.931.016. June 5, 1990.

16. Worthington P, Branemark P. Advanced osseointegration surgery: application in the maxillofacial region. Chicago: Quintes; 1992. $233 \mathrm{p}$.

\section{ABOUT THE AUTHOR}

\section{Ashish R Jain}

Senior Lecturer, Department of Prosthodontics, Tagore Dental College and Hospitals, Chennai, Tamil Nadu, India, Phone: 0442614439 e-mail: dr.ashishjain_r@yahoo.com 